\title{
E-learning in Higher Educational Institutions in Kuwait: Experiences and Challenges
}

\author{
Mubarak M Alkharang, George Ghinea \\ Department of Information Systems and Computing \\ Brunel University \\ London, UK
}

\begin{abstract}
E-learning as an organizational activity started in the developed countries, and as such, the adoption models and experiences in the developed countries are taken as a benchmark in the literature. This paper investigated the barriers that affect or prevent the adoption of e-learning in higher educational institutions in Kuwait as an example of a developing country, and compared them with those found in developed countries. Semistructured interviews were used to collect the empirical data from academics and managers in higher educational institutions in Kuwait. The research findings showed that the main barriers in Kuwait were lack of management awareness and support, technological barriers, and language barriers. From those, two barriers were specific to Kuwait (lack of management awareness and language barriers) when compared with developed countries. Recommendations for decision makers and suggestions for further research are also considered in this study.
\end{abstract}

Keywords-e-learning; higher education; adoption; Kuwait; developed countries; e-learning barriers.

\section{INTRODUCTION}

E-learning has emerged as a necessity to meet the challenges posed by the development of information technology and its potential for greater access to knowledge [1]. E-learning was first introduced in developed countries; thus, the adoption and utilization models developed there have been taken as benchmarks worldwide. Essentially, the influential factors and barriers to the adoption of e-learning within different societies and region may or may not be the same as for those identified in developed regions, with varying degrees of intensity or importance [2]. Accordingly, the models available for adoption may not be applied across all steps and phases when utilized by different societies and countries. As such, influential factors and barriers to e-learning may vary between cases.

In regard to educational establishments across the globe, elearning is becoming more widely adopted. As with many different countries, the adoption of e-learning in the context of higher educational institutions has become the subject of much research and examination. Importantly, regardless of the high standards of living within the country, Kuwait is falling behind other countries because of its relatively poor innovation and productivity capabilities [3]. With this noted, it is essential that organizations and the government work together in order to update and upgrade the skills of their subjects, whether employees, customers or students, and to further deliver ongoing learning and training where e-learning is still to play a key role [4].
The aim of this research is to investigate and identify factors that will mostly influence the adoption of e-learning in Kuwait as an example of a developing country, and compare them to those found in developed countries. In order to achieve this aim, our research was conducted in two phases. The first was based on reviewing and examining the existing literature and studies on e-learning, highlighting the factors that influence the adoption of e-learning. The second phase comprised empirical data collection, where semi-structured interviews were conducted in Kuwait. The results of this study will help decision makers to gain a better understanding of the factors that determine and influence the adoption of e-learning in higher educational institutions in Kuwait.

The structure of this paper is as follows; the next section introduces e-learning in terms of definition, history, and advantages. Then, the main factors and barriers to e-learning adoption in developed countries are highlighted. After that, the empirical background to this study is presented and followed by the research methodology. The following section discusses and compares the research findings. Finally, the paper concludes by discussing the implications of the study's findings, and identifying future research directions.

\section{INTRODUCTION TO E-LEARNING}

\section{A. Definition of e-Learning}

The term e-Learning devotes to electronic learning, which was defined by the NCSA e-Learning group as "the acquisition and use of knowledge distributed and facilitated primarily by electronic means. This form of learning currently depends on networks and computers but will likely evolve into systems consisting of a variety of channels (e.g., wireless, satellite), and technologies (e.g., cellular phones, PDAs), as they are developed and adopted. E-learning may incorporate synchronous or asynchronous access and may be distributed geographically with varied limits of time" [5]. While Koohang \& Harman [6] defined e-learning as:

"The delivery of education (all activities relevant to instructing, teaching, and learning) through various electronic media. The electronic medium could be the Internet, intranets, extranets, satellite TV, video/audio tape, and/or CD ROM."

\section{B. History of e-Learning}

Since the 1960s, educators and trainers at all levels of education, business, training and military made use of technology and computers in different ways to support and 
enhance learning [7]. Accordingly, in the early 1960s, Don Bitzer at the University of Illinois created a timeshared computer system called PLATO that was concerned with literacy programs. PLATO allowed students and teachers to use graphics terminals and TUTOR, an educational programming language, to communicate and interact with other users by means of electronic notes, thus being the forerunner of today's conferencing systems [7].

Nowadays, e-learning is evolving with the World Wide Web as a whole and it's changing to a degree significant enough to warrant a new name, namely e-learning 2.0. The term e-Learning 2.0 is used to refer to new ways of thinking about e-learning inspired by the emergence of Web 2.0. From an e-Learning 2.0 perspective, e-learning will concentrate on social learning and the use of social software such as blogs, wikis, podcasts and virtual worlds.

\section{Benefits and Drawbacks of e-Learning}

The significant shift towards e-learning is clearly motivated by the various advantages it offers. Despite the fact that elearning has received much commendation, it remains that human instructors will never be replaced completely by computer systems [8]. Nevertheless, establishing the benefits achievable through e-learning is important. It is recognized that some of the key benefits include the reduction of overall cost (instructors' salaries, travel costs, and meeting room rentals), as well as access to quality education, the provision of convenience and flexibility, a reduced environmental impact through lower paper use and energy consumption, and higher retention $[9,10]$.

Although the benefits and advantages of e-learning are obvious, it could be argued that it still has some weaknesses. For example, since users are not bound by time, the course is available $27 / 7$ and does not require physical attendance which could reduce the social and cultural interaction. The learners may also feel isolated and unsupported while learning since the instructors and instructions are not always available. They may become bored with no interaction. Technology issues required for e-learning could also become potential problems for the learning process. The learners need to have access to resources such as computers, internet, and software. They also need to have computer skills with programs such as word processing, Internet browsers, and e-mail $[11,12]$.

\section{BARRIERS TO E-LEARNING ADOPTION}

Reviewing the literature on e-learning practices shows common agreement on the importance of information and communication technology (ICT) in today's learning environment [13]. Most organizations have understood that elearning has to be integrated as part of daily tasks of students and employees (academics and managers), not to be seen as a separate tool or technique for learning and training. Therefore, e-learning has become a strategic advantage that participates in the realization of the organizational strategic plan [14].

Figure 1 shows the model of e-learning development found in developed countries and is adopted from the reviewed literature [2]. E-learning initiatives come about as a result of environmental trends which are made up of the same factors that are the cause and the consequence of the revolutionized technology, i.e. rapid change of technology and rapid change to learning environment. The outcome of these trends has been an increasing amount of pressure on educational organizations to use IT to improve their capacity to respond to learning needs. From this pressure, the decision to implement e-learning emerges.

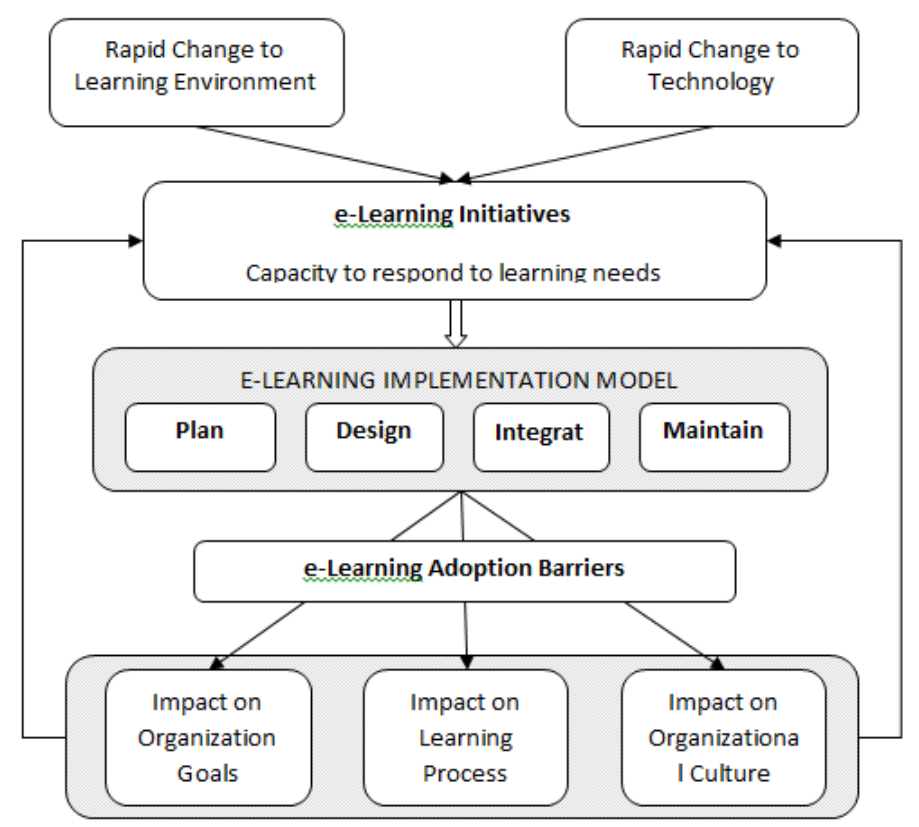

Fig.1. Development Model of e-Learning

The barriers to e-learning adoption can be found between the decision to implement e-learning and the impacts on the organization. The e-learning implementation model follows the usual implementation model of any type of information system, and it is made up of four stages: planning, designing, integrating, and improving [15]. The 'integration' stage marks the occasion when the system is put to work in the organization (i.e. the organizational implementation). The last stage of 'improvement' can only be carried out after the impacts on the organization have been evaluated, i.e. the impact on organization goals, the impact on learning process, and the impact on organizational culture.

Technology critics consistently argue for a balanced review of any technology, but the threats, challenges, and losses brought by technology are typically less discussed. While focusing on barriers might be construed negatively, it is not intended to dissuade organizations or individuals from using learning technologies. Rather, the aim is to increase awareness and understanding in regard to the overall nature of issues experienced by e-learners. Such an examination is critical considering the heavy investments, promises, and exponential growth associated with e-learning.

Thus, according to Bernárdez [16], the barriers to the implementation and adoption of e-learning can be related to personal issues, technical issues, or organizational issues. The most commonly cited personal barriers are time management problems, language problems, attitude towards e-learning and learning styles or preferences where learners might prefer passive or active learning. The technical barriers include 
infrastructure building and upgrading, maintaining connectivity and bandwidth, accessibility and usability, and lack of technical support. The organizational barriers include lack of e-learning awareness, lack of management support and commitment, lack of strategic planning and direction, lack of time available for learning and training, lack of appropriate content and assessments, and lack of incentives and credibility [17, 18].

After reviewing the literature and highlighting the main problem areas, important factors and key barriers were grouped into four main categories: cost, time, technology, and attitude. Importantly, cost is commonly highlighted as being one of the most notable of barriers facing e-learning. Technology is fundamental within e-learning, and it is also expensive and unpredictable, which makes the initial costs of implementation and on-going costs of maintenance very high $[19,20]$.

Moreover, time here refers to the amount of time required to establish and maintain e-learning within organizations. It also refers to the amount of time made available by both organizations and learners for e-learning. Considering external interruptions and distractions to the learners and maintaining the appropriate concentration for e-learning, the time factor is a significant barrier to e-learning. In fact, it occupies an important rank among the top barriers to adopting e-learning in organizations [20, 21].

Likewise, technology is critical in adopting e-learning. It requires adjustments from both, learners and organizations. For organizations to effectively implement e-learning, they need to ensure that they have the appropriate capacity to run e-learning systems and that serious consideration is given to hardware compatibilities and capabilities. Inadequate software, limited bandwidth and connectivity, and system breakdowns are other problems [22]. Technical support is also a significant issue, especially in cases where the suppliers do not provide this service. In such a scenario, the users may become reluctant to use e-learning. Horton [23] for instance claims that many elearning courses are dead on arrival due to an inability to install the right software, establish connectivity, or provide support.

Furthermore, the attitude towards e-learning is important. To achieve the promises of e-learning, users need to embrace it and management needs to provide the necessary support. Essentially, if they feel that e-learning creates more problems than it solves or if they simply do not know how to use it, all involved will not be comfortable with its use, and will therefore demonstrate signs of resistance, thus rendering the e-learning system valueless [20, 22].

\section{ADOPTION OF E-LEARNING IN KUWAIT}

The ever-growing use and adoption of information and communication technologies by the Kuwaiti government departments and organizations have helped build an IT infrastructure capable of adopting new technologies such as ecommerce, e-government, and e-learning [24]. The term elearning is relatively new in Kuwait, and only a limited number of local suppliers offer e-learning systems, currently implemented in some of petroleum and financial companies. Nevertheless, an increasing number of organizations are responding to the challenge of e-learning and are moving to adopt it, yet are finding significant barriers hampering their efforts $[3,25]$.

Importantly, however, there is a limited number of studies on the field of e-learning implementation and adoption in Kuwait, and very few researches have been carried out on the barriers encountered by organizations and higher educational institutions using this relatively new learning method $[2,25]$. It should be acknowledged that, in the country, technological use is expanding, and the use of the Internet, more specifically, is garnering much attention. According to the Arab Human Development Report [26], the number of Internet users in 1990 was $0 \%$, while in 2003 the number was $23 \%$ and in 2009 this had increased to $37 \%$. Hence, while considering the international movements towards an information-based society and underlining e-learning as a means to improve the learning and training of organizations, the evolution of technology and Internet in Kuwait and the barriers and recommendations that will be addressed in this study should be taken into consideration when adopting any e-learning system in Kuwait.

As stated before, e-learning as an organizational activity started in the developed countries, and as such, the implementation models developed in the developed countries are taken as a benchmark. Furthermore, the factors and barriers that influence the adoption of e-learning in different regions and societies may or may not be the same as those found in the developed countries with varying degrees of intensity or importance. Hence, those available implementation models may not necessarily be followed in all stages and steps when used by different countries and societies. Accordingly, the implementation barriers and the influential factors may differ from one case to another.

\section{RESEARCH MethodOLOGY}

A qualitative approach was used for this study in order to explore and study emerging phenomena within their context. Based on Denzin and Lincoln's [27] recommendations, the data collection was carried out through direct contact with the main higher educational institutions in Kuwait, where there are five universities and six colleges. Of these, there is only one public university (Kuwait University, KU) and one public college (Public Authority of Applied Education and Training, PAAET). Six higher educational institutions were chosen, representative of the biggest numbers of students and staff in Kuwait.

The study was limited to higher educational institutions' academics and managers in Kuwait, where fifteen members of the chosen organizations were contacted. The sample was chosen for convenience and practical reasons since knowing their opinions and perceptions will help to improve the services provided by this technology. Further, they were chosen because universities' academics and managers are amongst those whose attitudes and supports will influence the adoption of e-learning in their organizations [3].

The data collection was based on semi-structured interviews [28-30]. Questions covered in the interview guide were laid out in three sections. The first section targeted general and historical background information on e-learning in the organization. The second section sought to identify the 
barriers and challenges faced in implementing and adopting elearning in the organization, focusing on identifying the most significant barriers by both management and users. The third section was about evaluating the e-learning experience in the organization.

The interview guide was reviewed and evaluated by three elearning practitioners and researchers. Based on their pilot evaluations and recommendations, the questions were revised and modified [31]. The interviews were conducted over a period of 6 weeks. Most of the interviews lasted between 60 and 90 minutes. Each interview was tape recorded and transcribed. These were given back to each participant to check any differences that may have arisen and to eliminate any bias [32].

In this study, the data were analyzed using thematic analysis [33], where the qualitative information were encoded in order to identify specific themes; that is, whether some sort of patterns are identified within the information that may have some relevance to the area of research [33, 34]. Thematic analysis steps suggested by Braun and Clarke [35] were followed. These steps start by reading and familiarizing with the data, generating initial codes by organizing the data, searching for themes by re-reading and reviewing the data, and defining and naming these themes.

\section{RESEARCH FINDINGS AND DISCUSSION}

The research findings offer insights into the main and influential factors that influence the adoption of e-learning in higher educational institutions in Kuwait. After summarizing the data collected and highlighting the main points, common themes were regrouped and key points and problem areas were divided into three main categories. These categories are management awareness and support, technology, and language barriers.

\section{A. Management Awareness and Support}

The main part of the study was to identify the key factors influencing the organizations surveyed from building an environment supportive of e-learning. The vast majority of those questioned on the limitations of e-learning (12 out of 15 respondents) stated lack of management awareness and support as the main barrier. In most cases, the strategy of the management in the organization was not in line with the intention to build an e-learning culture. E-learning was seen by the management as a waste of time process and an ineffective option for learning. One of the IT specialist said "Of course, a supportive management is a key factor for the acceptance of any new project including e-learning. However, the management will not support e-learning unless they are aware of the benefits it offers, and unfortunately our management is unaware of the benefits and strategic advantages of e-learning". This was more obvious in the replies of interviewees working in public higher educational institutions in Kuwait. In such cases, the top management are more concerned with their own image and profit, rather than the organization's image. However, in the private educational institutions, the management is more concerned with a return on investment and therefore adopting e-learning has a higher priority than in public organizations.
Since the management was the source of resistance, the lower level employees did not sincerely buy into the e-learning projects. There was a "lack of understanding about $e$ learning", as one of the respondents mentioned in describing the organization environment. As a result, even when elearning did deliver benefits, they were hampered by the intergroup conflict in the organizations. Other interviewees stated that the management lacked the awareness of the strategic benefits of e-learning. Such a lack of awareness was felt through the absence of clear training and learning policies aimed at developing the knowledge and skills of their staff. Some interviewees mentioned that some managers and academics were computer illiterate; thus, they were afraid of the new technology and more comfortable with the traditional methods. One of those interviews said "How would you convince those old people to use e-learning while they don't know how to use computers?". Interestingly, an academic stated that the content development in the e-learning modules was very poor and there was a limited involvement in the contents development process. As a consequence, many academics did not feel motivated to use the e-learning system and showed high levels of resistance and reluctance.

Nevertheless, the key lesson which has been derived from this factor is that the problem is not one of structure but of processes. The difficulty consists in knowing the management processes that lead to a successful adoption of e-learning. The management in the surveyed educational organizations has failed to understand the strategic advantages of using e-learning as a means to improve the learning process.

\section{B. Technology Barriers}

Technology problems came high in the list of barriers in Kuwait where they were mentioned by 10 out of 15 participants. Bandwidth and internet speed limitations were seen as significant barriers to starting and adopting e-learning in the educational organizations. Some interactive tools and multimedia simulations take far too long for the user to access and use. This was apparent in organizations that did not have appropriate infrastructure that support the e-learning system. Furthermore, technology standards were seen by IT specialists in the organizations as an important requirement for e-learning success. One said that "we need to standardize the procedures, formats and systems within the organization". Those standards act as the base to use physical and intellectual IT assets. In addition, some academics said that the absence of technical support would be a triggering factor for ending the e-learning project since most of the users are not familiar with e-learning technologies and procedures.

The findings also revealed that more than half of participants ( 8 out of 15) were worried about security and confidentiality issues. Security and confidentiality concerns are seen mostly by academics as one of the most important issues due to the sensitivity of information being transferred online such as assessments and grades. A system administrator said "Security aspects and data confidentiality are very important to accept and use e-learning by academics. However, they have less effect on the students' perceptions". Security issues include computer and network security, privacy and confidentiality of data. Underrating the importance of this 
factor could cause unauthorized access to sensitive information and loss of users' trust, which might hinder the adoption of elearning. Surprisingly, one member of the top management was concerned with system integration where local systems are linked together and contain all different functions which would provide a full and real one stop shop. It is common for different departments to have different software and hardware that may not work together which may lead to e-learning implementation and adoption difficulties.

The technological problems mentioned by the interviewees were critical for the adoption of e-learning in Kuwait. Regardless of the fact that the necessary resources and equipment (personal computers in particular) for using elearning were made available in most of the educational organizations surveyed, all interviewees mentioned that there was plenty of room for improvement and the intensity of barriers was strong enough to wear away the positive effects obtained from e-learning. This is mostly due to the lack of appropriate implementation of the e-learning implementation model mentioned earlier (Figure 1). The implementation model of e-learning in Kuwait was not made up of the four usual stages but only one: integration, while there was not much concern about planning, designing or evaluating the e-learning investments.

\section{Language Barriers}

Language barriers were found to be significant barriers, having been mentioned by 9 out of the 15 interviewees. Most of the e-learning contents used in the organizations were developed in English, and many of those organizations had a large number of employees who did not master the English language. Those who did not master the English language either conducted their education in non-English countries or their fields are not English specialty, hence they were reluctant to use e-learning. Language barriers were also mentioned by academics who feel students in higher educational institutions in Kuwait will feel uncomfortable when using e-learning courses that were developed in English. Those students have normally undertaken all their previous education in Arabic, speaking English as a second language and have varying levels of English proficiency. One interviewee mentioned that some departments in the organization were not English literate; and thus, they were afraid of the new system that does not support their language. He said "departments such as Law and Arabic Literature provide their teaching and course contents in Arabic, hence the academics and students there will be reluctant to use the e-learning system if not customized and translated to Arabic".

Meanwhile, the cost for developing Arabic contents and courses was very expensive and logistically complicated for many of these organizations. The Arab Human Development Report [26] urged the governments and policy makers in the Arab states to encourage and reward professionals and entrepreneurs to develop content in Arabic that incorporated different aspects of the culture and tradition and publish it on the Internet. It seemed that progress was still slow in content development and the organization environment still relied on contents and courses developed in English for e-learning. The fact that language is recognized as a significant barrier in
Kuwait is a reflection of the ready-to-wear approach that the participated organizations have followed with little consideration to content appropriateness or culture.

\section{BARRIERS COMPARISON BETWEEN KUWAIT AND DEVELOPED COUNTRIES}

A comparison (using a simple 3-point scale, irrelevant, relevant, or important) of barriers between the Kuwaiti and developed countries experiences is shown in Table 1. The comparison was established by ranking the barriers according to their degree of importance.

TABLE I. COMPARISON OF BARRIERS BETWEEN KUWAIT AND DEVELOPED COUNTRIES

\begin{tabular}{|c|c|c|}
\hline Barriers & $\begin{array}{c}\text { Developed } \\
\text { Countries }\end{array}$ & Kuwait \\
\hline Cost & Important & Irrelevant \\
\hline Time & Important & Relevant \\
\hline Technology & Important & Important \\
\hline Attitude & Important & Relevant \\
\hline $\begin{array}{c}\text { Management } \\
\text { Awareness and } \\
\text { Support }\end{array}$ & Relevant & Important \\
\hline \begin{tabular}{c} 
Language \\
\hline
\end{tabular} & Irrelevant & Important \\
\hline
\end{tabular}

From the literature [19-22], the order of priorities of barriers found in developed countries was cost, time, technology, attitude, management awareness and support, and language. In comparison, the order of priorities found in Kuwait in this study was management support, language, technology, attitude, time, and cost. Looking at the two rankings, only technology shares the same degree of importance. However, in the remaining barriers, Kuwait varies from developed countries which support our view in that the barriers in different regions and societies may or may not be the same as those found in the developed countries with varying degrees of intensity or importance. In the developed countries, cost, time, and attitude barriers ranked highly as important. In Kuwait, time and attitude appeared as relevant, and cost was considered irrelevant. On the other hand, management support and language barriers were rated as highly as important in Kuwait, whereas in developed countries, management support barriers are considered relevant and language barriers considered irrelevant.

In Figure 1, the decision to implement e-learning in developed countries is followed by an implementation model which consists of the usual four stages: planning, designing, integrating and improving. From the research findings, the implementation model of e-learning in Kuwait did not embrace the four usual stages but only one: integration. Unfortunately, there was not much concern in the participating organizations about planning, designing or evaluating the e-learning investments. 


\section{CONCLUSION}

The aim of this research is to investigate and study the factors that influence the adoption of e-learning in higher educational institutions in Kuwait, and help to reduce the resistance towards using e-learning. Therefore, we have to find and study all the factors that influence the success of e-learning in order to successfully reach the adoption of the e-learning. In this study we have introduced and analyzed some factors that influence the acceptance and adoption of e-learning in developed countries in general, and specifically in Kuwait as an example of a developing country. The importance and intensity of barriers to e-learning adoption found in developed countries were found to be different from those found in Kuwait. Furthermore, the implementation model of e-learning established in developed countries was not followed in all stages when implemented in Kuwait. The research findings confirm the research assumptions in that the factors and barriers that influence the adoption of e-learning in different regions and societies may not be the same as those found in the developed countries with varying degrees of importance. Hence, those available implementation models may not necessarily be followed in all stages and steps when used by different countries and societies.

Limitations to this study revolved around the lack of up-todate data on the state of using e-learning in higher education institutions in Kuwait. There were no formal statistics on elearning projects and plans for those specific institutions. Lastly, the hectic schedule of some of the participants made it difficult to complete the interviews without interruptions. In spite of those limitations, it is believed this study would offer firm indications about the current state of e-learning, and provides a contribution to the growing literature on e-learning in Kuwait.E-learning adoption in developing countries is a huge project, with many criteria that may not be necessary the same as those found in the developed countries. In Kuwait, the impact of e-learning so far has failed to deliver benefits, and improvements have rarely matched expectations. The lack of awareness of the potential benefits to be accrued from creating an e-learning culture in which technology is a facilitator does create some confusion. However, there were indications and hopes that it is only a matter of time before e-learning is fully appreciated and adopted in Kuwait.

\section{REFERENCES}

[1] Bottino, R.M., The evolution of ICT-based learning environments: which perspectives for the school of the future? British Journal of Educational Technology, 2004. 35(5): p. 553-567.

[2] Ali, G.E. and R. Magalhaes, Barriers to implementing e-learning: a Kuwaiti case study. International journal of training and development, 2008. 12(1): p. 36-53.

[3] Aldhafeeri, F., M. Almulla, and B. Alraqas, TEACHERS EXPECTATIONS OF THE IMPACT OF E-LEARNING ON KUWAITS PUBLIC EDUCATION SYSTEM. Social Behavior and Personality: an international journal, 2006. 34(6): p. 711-728.

[4] Al-Kazemi, A.A. and A.J. Ali, Managerial problems in Kuwait. Journal of Management Development, 2002. 21(5): p. 366-375.

[5] Meyen, E.L., et al., e-Learning: A programmatic research construct for the future. Journal of Special Education Technology, 2002. 17(3): p. 3746.

[6] Koohang, A. and K. Harman, Open source: A metaphor for e-learning. Informing Science: International Journal of an Emerging Transdiscipline, 2005. 8: p. 75-86.
[7] Nicholson, P., A History of E-Learning, in Computers and Education, B. Fernández-Manjón, et al., Editors. 2007, Springer Netherlands. p. 1-11.

[8] Mouzakitis, G.S., E-Learning: The six important "Wh...?". Procedia Social and Behavioral Sciences, 2009. 1(1): p. 2595-2599.

[9] Gill, M., "E-learning technology and strategy for organisations". The Business of E-learning: Bringing your Organization in the Knowledge Economy, University of Technology, Sydney, 2000.

[10] Roy, R., S. Potter, and K. Yarrow, Designing low carbon higher education systems: Environmental impacts of campus and distance learning systems. International journal of sustainability in higher education, 2008. 9(2): p. 116-130.

[11] Welsh, E.T., et al., E-learning: emerging uses, empirical results and future directions. International Journal of Training and Development, 2003. 7(4): p. 245-258.

[12] Collins, C., D. Buhalis, and M. Peters, Enhancing SMTEs' business performance through the Internet and e-learning platforms. Education+ Training, 2003. 45(8/9): p. 483-494.

[13] Lytras, M.D., A. Pouloudi, and A. Poulymenakou, Knowledge management convergence-expanding learning frontiers. Journal of knowledge management, 2002. 6(1): p. 40-51.

[14] Magalhães, R., Organizational knowledge and technology: an actionoriented perspective on organization and information systems. 2004: Edward Elgar Publishing.

[15] Alter, S., Which life cycle---Work system, information system, or software. Communications of the AIS, 2001. 7(17): p. 1-52.

[16] Bernárdez, M., From E-Training to E-Performance: Putting Online Learning To Work. Educational Technology, 2003. 43(1): p. 6-11.

[17] Al-Shery, A., et al. The Motivations For Change Towards EGovernment Adoption: Case Studies From Saudi Arabia. 2006.

[18] Mungania, P., The seven e-learning barriers facing employees. Retrieved November, 2003. 18: p. 2004.

[19] Murray, D. E-learning for the workplace: Creating Canada's lifelong learners. 2001: Conference Board of Canada.

[20] Simmons, D.E., The forum report: E-learning adoption rates and barriers. The ASTD e-learning handbook, 2002: p. 19-23.

[21] Baldwin-Evans, K., Employees and e-learning: what do the end-users think? Industrial and Commercial Training, 2004. 36(7): p. 269-274.

[22] Netteland, G., B. Wasson, and A.I. Mørch, E-learning in a large organization: A study of the critical role of information sharing. Journal of Workplace Learning, 2007. 19(6): p. 392-411.

[23] Horton, W., e-Learning by Design. 2011: Wiley.

[24] Al-Fadhli, S., Instructor Perceptions of E-learning in an Arab Country: Kuwait University as a case study. E-Learning and Digital Media, 2009. 6(2): p. 221-229.

[25] Al-Fadhli, S., Factors Influencing the acceptance of distance-learning. International Journal of Instructional Media, 2011

[26] UNDP, Arab Human Development Report-UNDP (2009), Challenges to Human Security in the Arab Countries. 2009.

[27] Denzin, N.K. and Y.S. Lincoln, The discipline and practice of qualitative research. Handbook of qualitative research, 2000. 2: p. 1-28.

[28] Myers, M.D. and D. Avison, Qualitative Research in Information Systems autofilled . 2002.

[29] Patton, M.Q., Qualitative research. 2005: Wiley Online Library.

[30] McMillan, J.H. and S. Schumacher, Research in education. 2009: Pearson Education.

[31] Presser, S., et al., Methods for testing and evaluating survey questions. Public opinion quarterly, 2004. 68(1): p. 109-130.

[32] Irani, Z., et al., Evaluating e-government: learning from the experiences of two UK local authorities. Information Systems Journal, 2005. 15(1): p. 61-82.

[33] Bradley, E.H., L.A. Curry, and K.J. Devers, Qualitative data analysis for health services research: developing taxonomy, themes, and theory. Health services research, 2007. 42(4): p. 1758-1772.

[34] Hsieh, H.-F. and S.E. Shannon, Three approaches to qualitative content analysis. Qualitative health research, 2005. 15(9): p. 1277-1288.

[35] Braun, V. and V. Clarke, Using thematic analysis in psychology. Qualitative research in psychology, 2006. 3(2): p. 77-101. 